\title{
Acceptability of Routine HIV Testing by Pregnant Women in Lusaka District Ante Natal Urban Clinics in Lusaka, Zambia
}

\author{
Mercy Muyemba Kapembwa ${ }^{1 *}$, Catherine Ngoma², Maureen Makoleka ${ }^{2}$ \\ ${ }^{1}$ Lusaka College of Nursing, Lusaka, Zambia \\ ${ }^{2}$ School of Nursing Sciences, University of Zambia, Lusaka, Zambia \\ Email: *mmkapembwa@gmail.com
}

How to cite this paper: Kapembwa, M.M., Ngoma, C. and Makoleka, M. (2018) Acceptability of Routine HIV Testing by Pregnant Women in Lusaka District Ante Natal Urban Clinics in Lusaka, Zambia. Open Journal of Nursing, 8, 669-688. http://dx.doi.org/10.4236/ojn.2018.89050

Received: July 24, 2018

Accepted: September 26, 2018

Published: September 29, 2018

Copyright (c) 2018 by authors and Scientific Research Publishing Inc. This work is licensed under the Creative Commons Attribution-NonCommercial International License (CC BY-NC 4.0). http://creativecommons.org/licenses/by-nc/4.0/

\begin{abstract}
Background: Each year around 1.5 million women living with Human immuno deficiency Virus (HIV) become pregnant, and without antiretroviral drugs there is a chance that their child will become infected. Following the introduction of Routine Human immuno deficiency Virus testing policy in Zambia, the Human immuno deficiency Virus test is offered to all pregnant women unless they decline. However, more pregnant women are declining to be tested. Objective: The main objective of this study was to investigate factors that influence acceptability of routine HIV testing by pregnant women in Lusaka district urban clinics. Materials and Methods: A cross sectional study using a quantitative approach was conducted in Lusaka District clinics. The sample size was 366 ante natal pregnant women who were selected by simple random sampling, selected from three (3) selected research setting. The study population included pregnant women aged 15 to 49 years, coming for ante natal visit for the first time, before being tested for HIV, were eligible and agreed to participate in the study. A pretested semi structured interview schedule was used to collect data. Data were entered and analysed with Statistical Package for Social Sciences (SPSS) version 20 program. Chi-square was used to test for significant associations and Binary Logistic regression modelling was carried out to predict the outcome. A 5\% level of significance ( $\mathrm{p}$ value) 0.05 confidence interval was set. Results: Study findings revealed that majority $85.6 \%$ (317) of respondents indicated willingness to undergo routine HIV testing in pregnancy though $77.3 \%$ perceived it a compulsory test. Binary logistic regression revealed that maternal age, educational level and information education and communication (IEC) contributed significantly to the model. The odds revealed that acceptability of routine HIV testing by older pregnant women ( $37-49$ years) were 8 times $(\mathrm{OR}=7.67, \mathrm{p}=0.003)$
\end{abstract}


higher than the younger ones. The odds of acceptability by respondents with tertiary education were 141 times (OR-141.23, p-0.0001), likely to accept HIV testing than those with primary or no education. And the odds also revealed that acceptability by women who cited adequate IEC (OR-2.6, p-0.024) were 3 times higher than those who cited inadequate IEC. Conclusion: The study showed that majority of the pregnant women was willing to undergo Routine HIV testing however a percentage regarded the test as a mandatory test without any choice of denial. Therefore there is need to address some factors that are likely to affect the routine HIV testing and impede the success of implementation of the PMTCT programme in the country which goes beyond testing for HIV alone. Recommendations: Ministry of Health needs to provide health education messages in different tribes. $\mathrm{MOH}$ should also intensify male involvement in HIV Testing and Counselling. LDHO should consider training more community health care givers as Voluntary Counselling and Testing providers. The District should organize regular refresher courses and presentations on Routine HIV testing to health workers and Ministry of Health should consider conducting a country wide study.

\section{Keywords}

Acceptability, Pregnant Women, Routine, Male Partner, Labour and Delivery

\section{Introduction/Background Information}

HIV/AIDS is a global problem whose emergence has introduced new dimensions to health care delivery worldwide [1]. It has been estimated that 35.3 million people worldwide now live with HIV and some do not know that they are carrying the virus [2]. Each year around 1.5 million women living with HIV become pregnant, and without antiretroviral drugs (ARVs), there is a chance that their child would also become infected. However, among mothers that take a regimen of ARVs for the prevention of mother-to-child transmission (PMTCT), the risk of HIV transmission can be reduced [3].

Mother-to-child transmission (MTCT) of HIV occurs when an HIV-positive mother passes the virus to her child during pregnancy, labour, delivery or breastfeeding. Without treatment, the likelihood of HIV passing from mother-to-child is $15 \%$ - 45\% [4]. However, antiretroviral treatment (ART) and other effective interventions for the prevention of mother-to-child transmission (PMTCT) can reduce this risk to below 5\% [4].

The conventional form of HIV testing in antenatal clinics is called voluntary counselling and testing (VCT); this is when women are offered an HIV test [5]. An alternative model is routine HIV testing, which is an "opt out" approach where the HIV testing is part of the routine laboratory tests undertaken during all pregnancies. The woman has to be fully informed of the test and has the option to refuse it [6].

Numerous studies have found that switching from VCT to routine testing can 
dramatically improve uptake of testing in PMTCT Programmes [5] [7] [8]. It is also evident that in some "opt-out" settings women do not feel that HIV testing is their choice, but perceive testing as compulsory if they wish to access antenatal care. This shows that there is a discrepancy between global targets and local realities of antenatal HIV testing [5].

A study by [9] of India conducted on Private Health care violating pregnant women's right revealed that human rights violations on HIV testing occurred commonly in Private rather than Public hospitals. According to the participants, HIV testing often occurred without consent; there was little privacy and breaches of confidentiality were common place.

A study done in Burkina Faso, Kenya, Malawi and Uganda revealed that $92 \%$ of women reported being asked whether they consented to HIV testing, and $84 \%$ reported they had the right to refuse testing. In Uganda, many women also reported perceiving HIV testing as mandatory and a prerequisite for accessing antenatal care services. In a study conducted in Malawi, women described feeling unprepared for HIV testing in the context of pregnancy, which could have had a detrimental impact on their ability to cope with an HIV diagnosis [5].

Some studies have associated high levels of HIV, MTCT and PMTCT knowledge with lower acceptability of PMTCT; for example, one study by Avert [5] from south-west Nigeria revealed that while $99.8 \%$ of pregnant women were aware of HIV, had very high knowledge of MTCT (92\%) and PMTCT (91\%), $71 \%$ had negative views towards the PMTCT of HIV. This was due to other factors such as stigma and discrimination faced by HIV-positive pregnant women. In Ethiopia, 90\% of pregnant women had high knowledge on PMTCT but low utilization of HIV counselling and testing [10].

A study conducted in Nigeria on HIV voluntary counselling and testing of pregnant women in Primary Health Care centres in Ilesa, Nigeria, revealed that women with higher education have better knowledge of HIV transmission whereas low level of female education promotes ignorance about HIV transmission and its prevention, especially to the unborn child [11] [12].

However, a study conducted by [1] on VCT for HIV in Nigeria, revealed that the association between level of education and willingness to undergo testing was not clearly defined, as there was no consistent pattern. The study revealed that while almost all (94.1\%) respondents without formal or only primary level were willing, only $88.8 \%$ of those with tertiary education indicated their willingness to be tested.

In Kenya, 96.7\% of HIV negative pregnant women disclosed results compared to $46.2 \%$ of HIV positive pregnant women [13] [14] [15].

In Zambia, more than $90 \%$ of women attending ante natal care services are tested for HIV as compared to general adult population, where only $23 \%$ have been tested [16]. Despite the high numbers of HIV testing, pregnant women in Zambia face challenges like stigma and long distance to the health centres especially those living in the rural areas [17]. The Government through Ministry of 
Health in 2013 authorized the immediate operationalization of Option B+ to provide free life-long ART to all pregnant women living with HIV, regardless of their CD4 count. Infants are being provided with ARVs from birth through to six weeks regardless of feeding method.

Despite HIV testing, counselling and treatment services for pregnant women being offered at the ante natal clinics without a cost, some women are not willing to test for HIV. In Lusaka Urban district for instance, where the HIV prevalence rate among women between $15-49$ years is $19.4 \%$, some women are still not willing to be tested [18].

According to [19], the number of pregnant women who opt out after being counselled is still significant. For example the number of women who were counselled for HIV in Lusaka Urban District for a period of 5 years from 2010-2014 who opted out increased from 6\% - 10\%. It is clear that from the forgoing that there are still a significant proportion of pregnant women who are opting out of HIV testing despite the introduction of routine HIV testing, with the numbers of those opting out increasing in a number of Health Centres.

The reasons for refusing the testing are not clear. This study sought to find answers to improve acceptability of HIV testing in Zambia.

\section{Materials and Methods}

Research design: A cross-sectional study to determine acceptability of routine HIV testing by pregnant women in Lusaka urban district was used. The study employed quantitative approach. The data collection tool which was used is a semi-structured interview schedule.

Research setting. The study was undertaken in Lusaka urban district in Lusaka province. The respondents were seen at Maternal Child Health department as they were coming for their booking for focussed antenatal visits.

Study/target population: The study population included pregnant women aged 15 to 49 years, coming for ante natal visit for the first time, before being tested for HIV, were eligible and agreed to participate in the study.

Sample selection: The sample was obtained from the target population of the Expected Pregnancies for Lusaka urban district. The study was conducted in Lusaka urban, a population of women mixed of educated, uneducated, formal, informal employment and house wives. A simple random sampling was used to select the pregnant women who were attending antenatal care. The samplings were being conducted on any days of the visit at the study sites.

Sample size: The sample size was calculated using the prevalence formula. The proportion was set at $61 \%$ gotten from the average baseline coverage for initial utilisation of antenatal services by pregnant women in Lusaka Urban Health facilities that are, according to [19]. Confidence limit was $5 \%$ and confidence interval was set at $95 \%$ giving a sample size of 366 inclusive of a $10 \%$ non-response rate.

Pilotstudy: The sample for the pilot study comprised of $10 \%$ of the study 
sample, which was 37 respondents. The pilot study helped to pretest and identifies weaknesses in the data collection tools. After the pilot study, adjustments were made to the data collection tool as necessary.

Data collection tools. The data collection tools that were used in this study were a semi-structured interview schedule.

A pre-tested interview schedule, one in English and another translated into Nyanja was used to collect data. The tool comprised of questions that were either open or closed ended.

The semi-structured interview schedule comprised of three (3) sections. Section A consisted of questions on the respondents' socio-demographic data. Section B comprised questions eliciting information on acceptability of routine HIV testing. Section C elicited information on knowledge levels on PMTCT. Section D comprised questions eliciting information on social economic factors and Section E comprised questions eliciting information on service related factors.

Ethical consideration: Ethical approval and permission was sought from the Excellence in Research Ethics and Science (ERES) Converge and a written permission to conduct the study was obtained from Lusaka urban district Health Office (LDHO). Respondents were asked to sign a consent form or right thumb print for those who could not write.

\section{Results}

The total number of 366 ante natal pregnant women was enrolled in this study. The majority (48.6\%) of respondents interviewed were between 26 and 36 years, (39.1\%) were in the 15 - 25 years category while (12.3\%) were above 37 years age category (Table 1). The mean age of the respondents being $\bar{x}=28.18$ and SD was 7.55 . The larger percentage $(70.2 \%)$ were married, the singles were $(24 \%)$ while the least $(1.1 \%)$ were divorced. The majority $(99.45 \%)$ of the respondents were Christians with (0.55\%) being Moslems. Most (48.1\%) of these respondents had secondary education, with (33.1\%) having primary education, while (16.9\%) had tertiary education. Majority (31.7\%) were self-employed, (25.7\%) were house wives, $(25.1 \%)$ unemployed and (17.5\%) having a formal employment. Most (48.9\%) of the respondents had no income of their own, followed by (15.6\%) with an income of below K500 and only (15.4\%) reported to have an income of above K1500.00. The study further revealed that the majority (97.5\%) of respondents had high knowledge levels on PMTCT and that $92.1 \%$ had heard about PMTCT and routine HIV testing and of those who reported having heard of PMTCT, 76.6\% of the respondents said they had heard of it from health personnel. Respondents displayed high knowledge of mother to child transmission with $97.5 \%$ reporting that it was possible for the infected mother to transmit the virus to the unborn child, mentioned correct routes of transmission and 74.3\% of the respondents defined the HIV correctly.

Concerning acceptability of routine HIV testing, most (99\%) of the respondents stated that it was important to test for HIV in pregnancy but only $85.5 \%$ 
indicated willingness to undergo routine HIV testing in this pregnancy (Table 2). However, $77.3 \%$ of the respondents perceived routine HIV testing as a mandatory test (Figure 1).

Table 1. Demographic data.

\begin{tabular}{|c|c|c|c|}
\hline & Variable & Frequency & Percent \\
\hline \multirow{3}{*}{ Age } & 15 - 25 years & 143 & 39.1 \\
\hline & 26 - 36 years & 178 & 48.6 \\
\hline & $37-49$ years & 45 & 12.3 \\
\hline \multirow{7}{*}{ Marital Status } & Total & 366 & 100.0 \\
\hline & Single & 88 & 24.0 \\
\hline & Married & 257 & 70.2 \\
\hline & Separated & 11 & 3.0 \\
\hline & Divorced & 4 & 1.1 \\
\hline & Widowed & 6 & 1.6 \\
\hline & Total & 366 & 100.0 \\
\hline \multirow{7}{*}{$\begin{array}{c}\text { Religious } \\
\text { Denomination }\end{array}$} & Pentecostal & 142 & 38.8 \\
\hline & Seventh Day Adventist & 59 & 16.1 \\
\hline & Catholic & 82 & 22.4 \\
\hline & Jehovah's Witness & 21 & 5.7 \\
\hline & U.C.Z. & 24 & 6.6 \\
\hline & OTHER & 38 & 10.4 \\
\hline & Total & 366 & 100.0 \\
\hline \multirow{6}{*}{ Level of Education } & None & 7 & 1.9 \\
\hline & Primary School & 121 & 33.1 \\
\hline & Secondary School & 176 & 48.1 \\
\hline & College & 45 & 12.3 \\
\hline & University & 17 & 4.6 \\
\hline & Total & 366 & 100.0 \\
\hline \multirow{5}{*}{ Occupation } & House Wife & 94 & 25.7 \\
\hline & Self Employed & 116 & 31.7 \\
\hline & Formal Employment & 64 & 17.5 \\
\hline & Unemployed & 92 & 25.1 \\
\hline & Total & 366 & 100.0 \\
\hline \multirow{6}{*}{ Monthly Income } & None & 179 & 48.9 \\
\hline & Below K500 & 57 & 15.6 \\
\hline & K500 - K1000 & 49 & 13.4 \\
\hline & K1001 - K1500 & 25 & 6.8 \\
\hline & Above K1500 & 56 & 15.3 \\
\hline & Total & 366 & 100.0 \\
\hline
\end{tabular}


Table 2. Showing acceptability of routine HIV testing $(n=366)$.

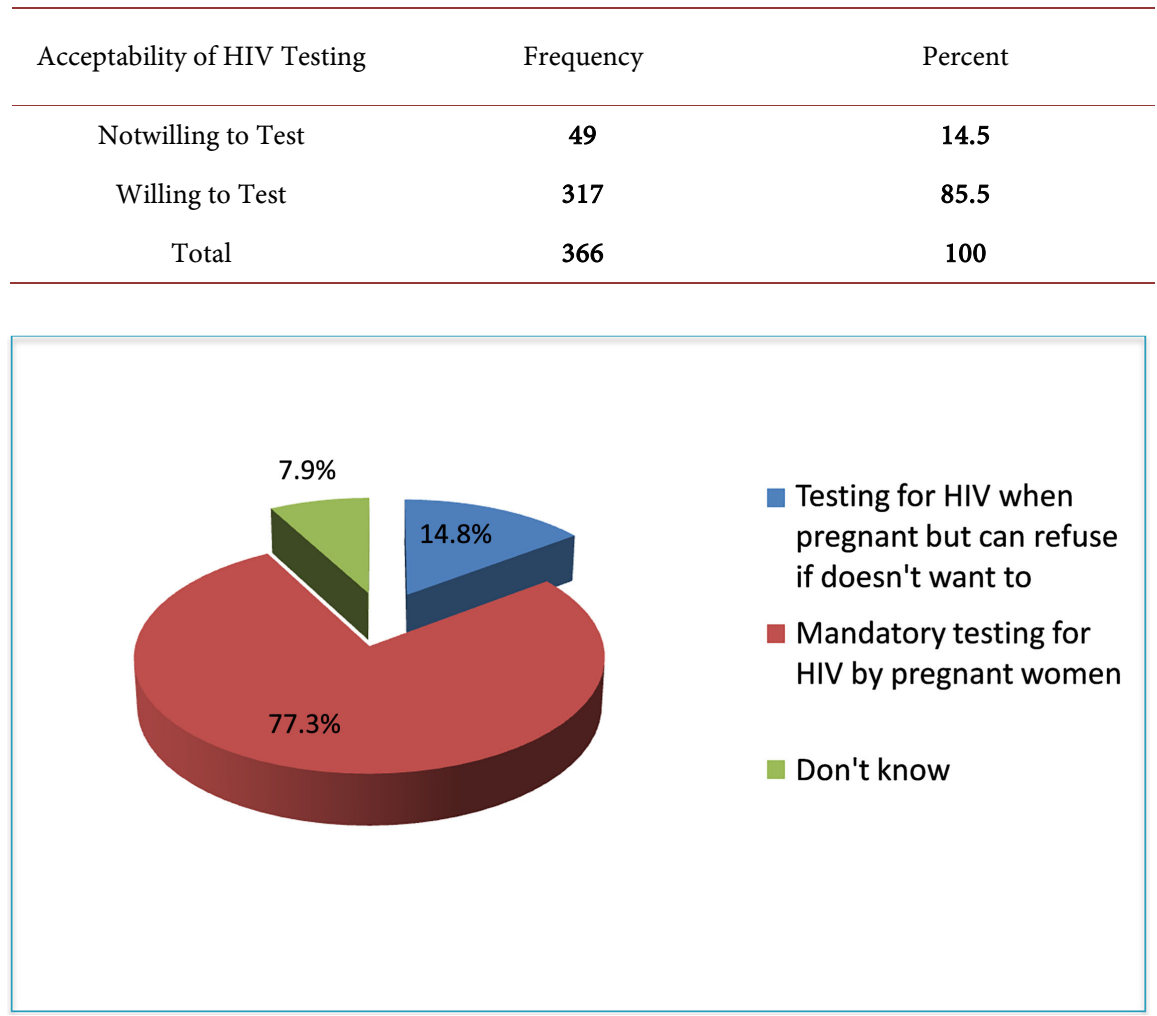

Figure 1. Perception of routine HIV testing by pregnant women $(\mathrm{n}=366)$.

On fear of spouse, $63.7 \%$ of respondents cited fear of spouse as compared to $36.3 \%$, most $(98.6 \%)$ of the respondents thought it was important to go with their spouses for HIV testing.

$37.4 \%$ stated that they would not disclose a HIV positive result and on perceived reaction of their spouses to HIV positive result, $37.4 \%$ said they would be accepted and understood, $45.9 \%$ of the respondents said their spouses would be angry at them, while $12.8 \%$ said they would be threatened with divorce and $3.8 \%$ of the respondents said they would suffer physical violence from their spouses.

Concerning stigma, $63.4 \%$ thought pregnant women do experience stigma when found HIV positive, $89.9 \%$ revealed that they would receive social support when found HIV positive but only $12.5 \%$ mentioned their spouses as a source of support. When asked what types of discrimination women face, $45 \%$ mentioned discrimination by the community, $27.2 \%$ reported that they face marital problems and 23.3 reported that HIV positive women are regarded as a burden by their families. Concerning Information, Education and Communication (IEC), the responses on whether respondents received adequate information, education and communication. Most (64.5\%) of the respondents reported to have had adequate IEC and (35.5\%) reported not having received adequate IEC. Of the respondents who were not satisfied with the counselling services offered at the health centre, $49.6 \%$ gave a reason that they were disturbed by other routine examinations carried out during group counselling and $50.4 \%$ said there was too 
much information given within a short time.

In relation to associations, acceptability of routine HIV testing by pregnant women has been associated with many factors by various studies. In this study, age in the range 37 - 49 years $(\mathrm{OR}=7.668, \mathrm{p}=0.003)$, maternal education $(\mathrm{OR}=$ $38.6, \mathrm{p}=0.001)$ and information education and communication $(\mathrm{OR}=2.6, \mathrm{p}=$ $0.024)$ were significantly associated with acceptability of routine HIV testing. This implies that age, education level and IEC plays a critical role in acceptability of routine HIV testing by pregnant women. Pregnant women who are older, with higher educational level and given adequate IEC by the health personnel were more likely to accept the routine HIV testing as compared to those who were younger, with low education level and not provided with adequate IEC.

Therefore we reject the null hypothesis that there is no association between acceptability of routine HIV testing by pregnant women and education level and IEC. The knowledge levels, stigma and fear of spouse did not have any significant association $\mathrm{p}$ value $>0.05$. In this study it means that knowledge levels $(\mathrm{p}=$ $0.839)$, stigma ( $\mathrm{p}=0.779)$, and fear of spouse $(\mathrm{p}=0.144)$ did not have any influence on acceptability of routine HIV testing by pregnant women.

Therefore, we accept the null hypothesis that states that there is no relationship between acceptability of routine HIV testing and knowledge of PMTCT and HIV. The odds were showing that a change in stigma from stigma to having no stigma increases the odds of acceptability to approximately 1 time [OR, (95\% CI) $=1.145(0.445-2.963)]$. A change in fear of spouse from "no fear" to "fear of spouse" reduces the odds of acceptability to approximately $2[\mathrm{OR},(95 \% \mathrm{CI})=$ $2.035(0.784-5.281)]$. The odds of acceptability of routine HIV testing with high knowledge levels were approximately $0.7[\mathrm{OR},(95 \% \mathrm{CI})=0.664,(0.46-9.682)]$ higher than those with low knowledge levels.

\section{Discussion}

\subsection{Knowledge and Acceptability of Routine HIV Testing by Pregnant Women}

The findings reveal that in the group that indicated acceptability of routine HIV testing, $98 \%$ had high knowledge levels while $2 \%$ had low knowledge levels. In the group that indicated non acceptability, 97.5\% had high knowledge levels while $2.5 \%$ had low knowledge. The pattern that emerges is that in both groups, knowledge levels were very high. Hence no difference was observed between the groups and with the $\mathrm{p}$ value of 0.765 , no significant correlation was observed between acceptability of routine HIV testing and knowledge levels on PMTCT and HIV testing in pregnancy. This could have been due to the result of having most (92\%) of the respondents having heard of PMTCT and $76.6 \%$ reported health personnel as a source of information of the respondents, $97.5 \%$ of the respondents thought it was possible to transmit the virus to the baby. These results are similar to findings by [10] of Ethiopia who reported that $94 \%$ of the pregnant women visited the health facility for ANC check-up. About $90 \%$ knew that a 
mother with HIV can pass the virus to her child but only about $18 \%$ and $9 \%$ of respondents attended the facility for HIV counselling and testing.

In this study, the results indicated that the odds of acceptability of routine HIV testing with high knowledge levels were approximately 0.7 [OR, $(95 \% \mathrm{CI})=$ 0.664, (0.46 - 9.682)] higher than those with low knowledge levels on PMTCT. However a study by [5] from south-west Nigeria revealed that while $99.8 \%$ of pregnant women were aware of HIV, had very high knowledge of MTCT (92\%) and PMTCT (91\%) but $71 \%$ had negative views towards the PMTCT of HIV. When asked the meaning of routine HIV testing, $77.3 \%$ responded that it was a mandatory test with no right to refuse.

These findings are similar to those in a study conducted by [20] in Kenya, revealed high number (92\%) of pregnant women being tested for HIV; however some of these women considered it mandatory.

\subsection{Social Demographic and Socio Economic Factors}

The social demographic characteristics of the respondents who participated in this study and were significant included age and level of education. Of the respondents interviewed, $48.6 \%$ were between 26 and 36 years and the mean age was $\bar{x}=28.18$ with a Standard Deviation (SD) of 7.55 (Table 1). This shows that the study sample consisted of youth who are at the peak of child bearing.

In the current study, the findings showed that acceptability of HIV testing decreased with age (Table 3 ). There was no significant association between acceptability of routine HIV testing and the respondents age $(\mathrm{p}=0.61)$. However, the multivariate analysis revealed that mothers in the age categories $15-25$ (39\%) and 26 - 36 (48.6\%), respectively, were less likely to accept routine HIV testing as compared to pregnant women (12.3\%) in the age range $37-49$ [OR, $(95 \% \mathrm{CI})=7.668(1.973-29.797)]$. This age effect was statistically significant ( $\mathrm{p}$ $=0.003)$. Therefore compared to older pregnant women, the younger pregnant women appear to be at risk of non-acceptability of routine HIV testing. These results are supported by the [18] which reported that older pregnant women were taking the HIV test than the young women; however, the CSO figures were higher (85.9\%) compared to the current study. This finding could be attributed to the fact that teenage mothers lack information about PMTCT. This assumption is contradicted by a study conducted in Bukina Fasso and Uganda by [21] which showed that older pregnant women $(78 \%)$ of more than 30 years were less likely to accept voluntary HIV testing as compared to the younger ones aged less than 19 years. On the other hand, [22] conducted a study in Kenya, revealed that acceptability levels between the young and the old were near equal. Concerning education levels of the respondents, the current study revealed that $48.1 \%$ had attained secondary school education. This result could be attributed to the fact the study was conducted in an urban setting where according to [18] report stated that women in urban areas are more likely to have a secondary education or higher than their rural counterparts. This implies that at least almost all the 
Table 3. Multivariate Binary Logistic Regression Model determining acceptability of HIV Testing among pregnant women.

\begin{tabular}{|c|c|c|c|c|}
\hline Independent variables & & Odds Ratio & 95\% Confidence Interval & p-value $(0.05)$ \\
\hline \multirow[t]{3}{*}{ Age } & \multicolumn{4}{|c|}{ Mother's Age (15 - 25) } \\
\hline & $2=26-36$ & 0.994 & $0.386-2.557$ & 0.990 \\
\hline & $3=37-49$ & 7.668 & $1.973-29.797$ & 0.003 \\
\hline \multirow[t]{5}{*}{ Marital Status } & \multicolumn{4}{|c|}{ Mother's Marital Status ( 1 = Married) } \\
\hline & $2=$ Single & 0.993 & $0.338-2.920$ & 0.990 \\
\hline & $3=$ Separated & 0.719 & $0.054-9.516$ & 0.803 \\
\hline & $4=$ Divorced & 0.970 & $0.046-20.392$ & 0.984 \\
\hline & $5=$ Widowed & 2.337 & $0.088-61.737$ & 0.611 \\
\hline \multirow[t]{4}{*}{ Occupation } & \multicolumn{4}{|c|}{ Mother's occupation status ( 1 = Employed $)$} \\
\hline & $2=$ House wife & 0.622 & $0.144-2.688$ & 0.525 \\
\hline & $3=$ Self Employed & 0.506 & $0.040-6.351$ & 0.598 \\
\hline & $4=$ Unemployed & 2.071 & $0.138-2.557$ & 0.990 \\
\hline \multirow[t]{3}{*}{ Education } & \multicolumn{4}{|c|}{ Mother's highest education level ( $1=$ None and primary $)$} \\
\hline & $2=$ Secondary & 21.826 & $4.188-113.736$ & 0.000 \\
\hline & $3=$ Tertiary & 141.232 & $21.653-921.653$ & 0.000 \\
\hline \multirow[t]{5}{*}{ Income } & \multicolumn{4}{|c|}{ Highest income $(0=$ None $)$} \\
\hline & $2=$ Below K500 & 8.856 & $0.685-114.432$ & 0.095 \\
\hline & $3=\mathrm{K} 500-\mathrm{K} 1000$ & 1.59 & $0.06-40.44$ & 0.916 \\
\hline & $4=\mathrm{K} 1001-\mathrm{K} 1500$ & 2.34 & $0.149-36.839$ & 0.545 \\
\hline & $5=$ Over K1500 & 0.182 & $0.011-2.964$ & 0.231 \\
\hline \multirow[t]{2}{*}{ Fear of Spouse } & \multicolumn{4}{|c|}{ Fear of spouse $(0=$ None $)$} \\
\hline & $1=$ Yes & 2.035 & $0.784-5.281$ & 0.144 \\
\hline \multirow[t]{2}{*}{ Stigma } & \multicolumn{4}{|c|}{ Stigma $(0=$ No $)$} \\
\hline & $1=$ Yes & 1.145 & $0.443-2.963$ & 0.779 \\
\hline \multirow[t]{2}{*}{ IEC } & \multicolumn{4}{|c|}{ Adequate information, education and communication $(0=\mathrm{No})$} \\
\hline & $1=$ Yes & 2.998 & $1.189-7.556$ & 0.020 \\
\hline
\end{tabular}

respondents were able to read and write. The findings show that $51 \%$ of the respondents who indicated acceptability of HIV routine testing had tertiary education levels as compared with the group $11.7 \%$ (37) that indicated non acceptability of HIV routine testing.

However, the trend reversed with those in the category of none, primary and secondary education where higher percentages indicated non acceptability (Table 3). The odds of acceptability for those with secondary levels of education were 22 times higher than those of primary or none education levels $(\mathrm{OR}=$ 21.826, $\mathrm{p}=0.001$ ). Similarly, those with tertiary education levels were 141 times more likely to exhibit acceptability than those whose levels of education were primary or none $(\mathrm{OR}=141.232, \mathrm{p}=0.001)$. This could be due to the fact that 
literacy enhances the ability of the patient to know their expectations from the health care and help make informed decisions concerning their health.

This finding is supported by studies done by [11] in Nigeria and [12] Banda (2012) in Zambia; found that women with higher education in their study had better knowledge of HIV transmission. This is important because educational attainment is one of the most influential factors affecting people's knowledge, attitudes and behaviors in various facets of life and has been shown to be an important determinant of health [18] (CSO, 2015). Contrary to the above findings, [1] in their study on Voluntary Counselling and Testing (VCT) for HIV in Nigeria showed higher levels of willingness to test for HIV among women without formal or only primary level education $(94.1 \%)$ and those with tertiary education (88.8\%).

Concerning fear of spouse, the study results revealed that there was a significant correlation between acceptability and fear of spouse, observed with a $p$ value of 0.000 . In the group that indicated acceptability, $40.8 \%$ had fear of spouse while $59.2 \%$ had no fear of spouse. This trend is reversed in the group that indicated non acceptability, where $67.2 \%$ had fear of spouse while $32.8 \%$ had no fear of spouse. The multivariate model revealed that fear of spouse did not have any significance on acceptability $(\mathrm{OR}=2.035, \mathrm{p}=0.144)$ though the odds were showing that a change in fear of spouse from "fear" to "no fear of spouse" increases the odds of acceptability to approximately 2 times [OR, $(95 \% \mathrm{CI})=2.035$ (0.784 - 5.281)] .

These odds findings are in line with the results in the current study where 98.6\% of the respondents thought it was important to go with their spouses for routine HIV testing. This is supported by [23] in Cambodia, who revealed that there was a strong association observed between acceptance and partner involvement but this was contradicted by [24] in Zambia, who reported that according to his findings $28 \%$ of $324 \mathrm{HIV}$ positive women of those counselled as a couple or alone, reported at least one adverse social event including physical violence, verbal abuse, divorce or separation.

On the issue of disclosure of HIV status to the spouse if tested positive, the current study revealed that $62.6 \%$ of the respondents reported that they would disclose the status while $37.4 \%$ revealed that they would not disclose. This is supported by [25] who reported that $43 \%$ of respondents were unable to disclose their status to their partner due to fear of spouse. [26] in Zambia reported that in Zambia the disclosure rate is varied in different studies and was found to be at $72 \%$ for both seropositive and seronegative patients among urban attendees in his study. This is echoed by [18] that reported that $97 \%$ of women who were tested during ANC and knew their test results disclosed them to someone, of these, $69 \%$ disclosed to their husbands. On the perceived reaction of the spouse to HIV positive results, $45.9 \%$ of the respondents in this study reported that their spouses would be angry at them, $12.8 \%$ would be threatened with divorce, and $3.8 \%$ would suffer physical violence from their spouses. Only $37.4 \%$ re- 
ported that their spouses would accept and understand. In support of these findings, [27] revealed that 83 out of 249 pregnant women in their study who refused HIV testing cited divorce as a perceived response of their husband following HIV positive test results.

With regards to the relationship between acceptability and stigma in the group that indicated acceptability, 49\% thought women experienced stigma while 51\% did not think so. In the group that indicated non acceptability $65.6 \%$ thought women experienced stigma while $34.4 \%$ did not think so. Hence it was observed that a higher percentage of those who indicated non acceptability thought women experienced stigma in comparison with those who indicated acceptability where a higher percentage did not think that women experience stigma. Chi-square results showed that there was a significant correlation between acceptability and stigma with a $\mathrm{p}$ value of 0.025 . After modelling with the multivariate model, it revealed that fear of spouse did not have any significance on acceptability ( $\mathrm{OR}=0.973, \mathrm{p}=0.950)$, the odds were showing that a change in stigma from no stigma to having stigma reduces the odds of acceptability to approximately 1 time $[\mathrm{OR},(95 \% \mathrm{CI})=0.973(0.418-2.266)]$. These findings are supported by [13] who revealed that there are associations of stigma measures with HIV testing refusal.

The current study revealed that $89.9 \%$ of respondents would receive social support after testing positive for HIV during pregnancy and only $12 \%$ named their spouses as a source of social support. [13] of Kenya and [15] of Ivory Coast reported similar findings that women who anticipated male partner stigma were more than twice as likely to refuse HIV testing.

This can be attributed to why in the current study, $63.4 \%$ of respondents thought that women do experience stigma after testing HIV positive and of these, $27.2 \%$ reported that women face marital problems while $49.6 \%$ said that HIV positive women are discriminated by the community.

\subsection{Service Related Factors}

The current study results revealed that among the respondents that indicated acceptability, $81.6 \%$ had adequate IEC ( $\mathrm{OR}=2.998, \mathrm{p}=0.020)$ while $18.4 \%$ had inadequate IEC. In the respondents that indicated non acceptability, $61.8 \%$ had adequate IEC while $38.2 \%$ had inadequate IEC. The pattern coming out is that a higher percentage of those that indicated acceptability had adequate IEC and a lower percentage had inadequate IEC in comparison with the group that indicated non acceptability. A change in IEC levels from inadequate to adequate increases the odds of acceptability by approximately 3 times [OR, $(95 \% \mathrm{CI})=2.998$ (1.189 - 7.556)]. A study done by [27] in Ethiopia showed that the pre-test counselling service being fair were 6 times more likely to refuse HIV testing than those who stated their impression on the pre-test counselling service being very good. This was also supported by a study by [28], in Nigeria that revealed that $29.5 \%$ of the $24 \%$ of the pregnant women, who had not undergone HIV Testing, 
did not undergo counselling. This is supported by similar findings by [29] in a study conducted in Malawi where antenatal mothers thought that they were inadequately prepared to undergo HIV testing. Contrary to the above studies, the current study findings revealed that $95.1 \%$ of the respondents reported having been counselled during this pregnancy while $4.9 \%$ reported not being counselled. This is supported by [18] findings which revealed that $95.5 \%$ of pregnant women in Lusaka were counselled for HIV testing.

On reasons for not being satisfied with the type of counselling services offered at the health centre, the current study revealed that $49.6 \%$ of those who were not satisfied cited being disturbed to go and do other routine exams during group counselling as the reason while $50.4 \%$ said during counselling, too much information was given within a short time. This is supported by [30] in Malawi who reported that some health care workers expressed concerns that the practice requires the woman to deal with too much information at once. [29] in South Africa who reported that clients had inadequate information on PMTCT services, given that they could not recall the information communicated to them during counselling.

On the duration of the pre-test counselling, the majority $68.4 \%$ reported having been counselled for more than 10 minutes. While only $6 \%$ of the respondents reported receiving counselling for less than 5 minutes.

The recommended minimum duration for giving IEC to clients at the health institution is 10 minutes [19]. This is contrary to the study results by [29] that indicated that $68 \%$ of the participants received less than 5 minutes of post-test counselling, $21 \%$ had 5 - 10 minutes, and only $10.7 \%$ had more than 10 minutes of post-test counselling.

This finding is supported by a study conducted by [25] in Zambia, which revealed that out of 120 respondents, $86.7 \%$ of the respondents reported that the duration of counselling was not enough to ask questions. The recommended duration reported to have been followed during counselling in the current study could have explained the high percentage of satisfaction with the type of counselling that was being offered.

\section{Conclusion}

The results of this study suggest that non-acceptability of routine HIV testing in pregnancy remains significant (14.5\%), and despite the high (85.5\%) uptake of HIV testing, the majority of people perceive the routine testing as a mandatory test with no right to refuse if not ready. Maternal age, education and information education and communication were found to be significant factors that affect acceptability.

\section{Limitations of the Study}

The study was only conducted in Lusaka Urban Health Facilities therefore the researcher will not generalize the research findings to the whole country. 
Use of cross sectional study designed its own limitations since the design does not provide definite information about cause-and-effect relationships. This is because in this design data is collected at one point in time and does not consider what happens before or after the data is collected.

\section{Recommendations}

Ministry of Health needs to provide health education messages in different tribes for broader communication. Ministry of Health should also intensify male involvement in HIV Testing and Counselling to promote disclosure of positive results. Lusaka District Health Office should consider training more community health care givers as Voluntary Counselling and Testing providers and to organize regular refresher courses on Routine HIV testing to health workers. Finally Ministry of Health to consider conducting a country wide study to capture those that are in the rural areas as well.

\section{Acknowledgements}

The authors are grateful to the Ministry of Health for sponsoring the research study. We also wish to thank to all the study participants for providing information at no cost.

\section{Conflicts of Interest}

The authors declare no conflicts of interest regarding the publication of this paper.

\section{References}

[1] Ekanem, E.E. and Gbadegesin, A. (2004) Voluntary Counselling and Testing (VCT) for Human Immunodeficiency Virus: A Study on Acceptability by Nigerian Women Attending Antenatal Clinics. African Journal of Reproductive Health, 8, 91-100. http://bioline.org.br

[2] WHO (2013) UNAIDS Report on the Global AIDS Epidemic. http://www.unaids.org/

[3] AVERT (2014) Prevention of Mother-to-Child Transmission (PMTCT) of HIV. http://www.avert.org

[4] WHO (2015) HIV/AIDS; Prevention of Mother to Child Transmission. http://www.who.int/hiv/topics/mtct

[5] AVERT (2014) Prevention of Mother to Child Transmission in Practice. http://www.avert.org

[6] MOH (2008) National Reproductive Health Policy.

[7] Rujumba, J. (2013) Pregnant Women's Experiences of Routine Counselling and Testing for HIV in Eastern Uganda: A Qualitative Study. BMC Health Services Research. http://www.biomedcentral.com

[8] Creek, T. (2007) Successful Introduction of Routine Opt-Out HIV Testing in Antenatal Care in Botswana. Lippincott Williams \& Wilkins Inc., Philadelphia.

[9] Madhivanan, P. (2014) HIV Testing among Pregnant Women Living with HIV in 
India: Are Private Healthcare Providers Routinely Violating Women's Human Rights? BMC International Health and Human Right.

[10] Deressa, W., et al. (2014) Utilization of PMTCT Services and Associated Factors among Pregnant Women Attending Antenatal Clinics in Addis Ababa, Ethiopia.

[11] Olanrewaju (2013) HIV Voluntary Counselling and Testing of Pregnant Women in Primary Health Care Centres in Ilesa, Nigeria. The Internet Journal of Third World Medicine, 6.

[12] Banda, J.M. (2012) Willingness to Accept HIV Testing among Caretakers with a Child Attending the University Teaching Hospital in Lusaka, Zambia. Medical Journal of Zambia, 39. http://www.ajol.info

[13] Turan, A.M., Bukusi, E.A., Onono, M., Holzemer, W.L., Miller, S. and Cohen, C.R. (2010) HIV/AIDS Stigma and Refusal of HIV Testing, among Pregnant Women in Rural Kenya: Results from the MAMAS Study, AIDS Behaviour. http://www.ncbi.nlm.nih.gov

[14] Muyanza, L. (2009) Difficulties of Disclosure of HIV Status to Sexual Partners among Expectant Women in Selected Clinics in Lusaka Urban. The University of Zambia. http://dspace.unza.zm

[15] Hermann, B. (2007) A Study in a PMTCT Programme, Abidjan When Do HIV-Infected Women Disclose Their HIV Status to Their Male Partner and Why? Ivory Coast. http://www.sajbl.org.za

[16] Rodregues, J. (2014) Zambia Policy Guidelines for EMTCT Option B+. IAAT, The Interagency Team on the Prevention and Treatment of HIV in Pregnant Women, Mothers and Children, New York.

[17] Torpey, K., Kabaso, M., Kasonde, P., Dirks, R., Bweupe, M. and Thompson, C. (2010) Increasing the Uptake of Prevention of Mother to Child Transmission of HIV Services in a Resource-Limited Setting. BMC Health Services Research, 10, 29. https://doi.org/10.1186/1472-6963-10-29

[18] CSO (2015) Zambia Demographic Health Survey (ZDHS). Lusaka.

[19] Lusaka District Health Management Office. MBB-MTEF Action Plan, 2013-2015.

[20] Hardon, A., et al. (2012) Women's Views on Consent, Counselling and Confidentiality in PMTCT: A Mixed-Methods Study in Four African Countries. BMC Public Health, 12, 26.

[21] Obermeyer, C.M. and Osborn, M. (2007) The Utilisation of Testing and Counselling for HIV: A Review of the Social and Behavioural Evidence. American Journal of Public Health, 97, 1762-1774.

[22] Mathingau, F.A. (2011) Factors Influencing Acceptance of Routine HIV Testing and Counseling among Pregnant Women in Kibera Informal Settlement, Nairobi, Kenya.

[23] Kakimoto, K., et al. (2007) Influence of the Involvement of Partners in the Mother Class with Voluntary Confidential Counselling and Testing Acceptance for Prevention of Mother to Child Transmission of HIV Programme (PMTCT Programme) in Cambodia. AIDS Care, 19, 381-384. http://www.tandfonline.com

[24] Semrau, K., Kuhnb, L., Vwalika, C., Kasonde, P., Sinkala, M. and Kankasa, C. (2005) Women in Couples Antenatal HIV Counselling and Testing Are Not More Likely to Report Adverse Social Events. AIDS, 19, 603-609.

[25] Masumo, M. (2009) Factors Influencing Partner Notification of HIV Status by Pregnant Women after Undergoing Routine HIV Testing at Antenatal Clinics in Kalomo District. University of Zambia, Lusaka. 
[26] Zimba, I. and Vwalika, B. (2010) Association between Unplanned Pregnancy and HIV Sero-Positivity Disclosure to Marital/Cohabitating Partner among Post-Natal Women in Lusaka, Zambia. Medical Journal of Zambia, 37, 205-215.

[27] Fanata, W. and Worku, A. (2012) Determinants for Refusal of HIV Testing among Women Attending for Antenatal Care in Gambella Region, Ethiopia. http://www.reproductive-health-journal.com https://doi.org/10.1186/1742-4755-9-8

[28] Kwampong, D.G. (2012) Health Service Barriers to HIV Testing and Counselling among Pregnant Women Attending Antenatal Clinic: A Cross-Sectional Study. BMC Health Services Research, 14, 267. http://www.biomedcentral.com/1472-6963/14/267

[29] Kalembo, F.W. and Zgambo, M. (2012) Loss to Follow Up: A Major Challenge to Successful Implementation of Prevention of Mother-to-Child Transmission of HIV-1 Programs in Sub-Saharan Africa. ISRN AIDS, 2012, Article ID: 589817. http://www.hindwi.com

[30] Odendal, T.M. (2014) Malawi Facing Challenges Implementing Option B+. http://www.aidsmap.com 


\section{Appendix}

\section{THE UNIVERSITY OF ZAMBIA \\ SCHOOL OF MEDICINE \\ DEPARTMENT OF NURSING SCIENCES}

SEMI STRUCTURED INTERVIEW SCHEDULE ON ACCEPTABILITY OF ROUTINE HIV TESTING BY PREGNANT WOMEN IN LUSAKA URBAN CLINICS, LUSAKA DISTRICT

\section{DATE OF INTERVIEW}

\section{PLACE OF INTERVIEW}

SERIAL NUMBER

\section{INSTRUCTIONS TO THE INTERVIEWER}

1) Introduce yourself to the respondent.

2) Ensure that the respondent is eligible for the interview and can be included in the study.

3) Explain the purpose of the study and assure respondent of confidentiality.

4) Request respondent for a written consent before you start the interview.

5) Do not write name of respondent on interview schedule.

6) Ensure that you get a response for each question.

7) Circle the most appropriate response, or write answer on space provided.

8) Provide time for respondent to ask questions at the end of the interview.

9) Thank the respondent at the end of the interview.

\section{Section A: Demographic Data}

1) What was your age at your last birthday?
a. 15 - 25 years
b. 26 - 36 years
c. 37 - 49 years

2) What is your marital status?
a. Single
b.Married
c. Separated
d.Divorced
e. Widowed

3) Which church do you belong to?
a. Pentecost
b.Seventh Day Adventist
c. Catholic
d.Jehovah's Witness
e. Other (specify)

4) What is your educational level?
a. None
b.Primary School 
c. Secondary School

d.College

e. University

5) What do you do for your living?

a. House Wife

b.Self employed

c. Formal employment

d.Unemployed

6) What is your monthly income?
a. None
b.Less than K500
c. Between K500 and K1000
d.Between K1000 and K1500
e. K2000 and above

7) Where do you stay/live (Residential area)?

\section{Section B: Knowledge of HIV Testing and PMTCT}

8) Have you heard of PMTCT?
a. Yes
b.No

9) If yes, which was your source of information?
a. Media
b.Health Personnel
c. Relatives
d.Friends
e. Others? Specify

10) What is HIV?

11) What is the meaning of routine testing for HIV?

a. Testing for HIV when pregnant but can refuse if doesn't want to

b.It is mandatory testing for HIV by pregnant women

c. Don't know

12) Do you think it is possible for an HIV infected woman to transmit HIV to her baby?
a. Yes
b. No

13) If yes to question 10, explain when can HIV be transmitted from the mother to the baby?
a. During pregnancy
b.During breast feeding
c. During delivery
d.During bottle feeding

14) Do you think it is important to test for HIV in pregnant?
a. Yes 
b.No

c. Don't know

15) If "yes" to question 14 then what are the benefits? (Tick all appropriate)

a. To protect the baby from getting the HIV virus from the infected mother

b.Medication is given to those that are HIV positive to prevent transmission of the virus

c. Women who are HIV negative are educated on how they can reduce risk of acquiring the virus

d.Other specify

\section{Section C: Acceptability of Routine HIV Testing}

16) Do you know your HIV status?

a. Yes

b.No

17) Would you like to be tested for HIV in this current pregnancy?

a. Yes

b.No

18) If No to question 17 above, state the reason why not?

\section{Section D: Socio Cultural Factors}

19) In your opinion, do you think it is important to come with your spouse for HIV testing?

a. Yes

b.No

20) Would you disclose your HIV status to your spouse if found HIV positive?

a. Yes

b.No

21) What would be the reaction of your spouse to the HIV positive results?

a. Accepted and understanding

b.Angry at wife

c. Physical violence towards wife

d.Threatened divorce

22) Would you receive any social support after testing positive for HIV in pregnancy?

a. Yes

b.No

23) If the answer is "yes", from whom?

a. Family

b. Friends

c. Church

d.Spouse

e. None

24) Do pregnant women experience any form of discrimination after testing positive for HIV? 
a. Yes

b.No

25) If answer is "yes" explain

\section{Section E: Service Related Factors}

26) Were you ever counselled about HIV testing during this pregnancy?
a. Yes
b. No

27) If yes how many times were you counselled?

a. One

b. Two

c. More than two

28) How long was the pre-test counselling session?

a. Less than 5 minutes

b.Between 5 - 10 minutes

c. More than 10 minutes

29) Were you satisfied with the type of counselling services or information provided at your centre regarding routine HIV testing?

a. Yes

b. No

30) If the answer is "No" give reason 